\title{
Composition and Optical Dispersion Characterization of Nanoparticles ZnO-NiO Thin Films: Effect of Annealing Temperature
}

\author{
Saad F. Oboudi ${ }^{1, *}$, Nadir F. Habubi ${ }^{2, \star *}$, Ghuson H. Mohamed ${ }^{1}$, Sami S. Chiad ${ }^{2}$ \\ ${ }^{1}$ Physics Department, College of Science, Baghdad University, Baghdad, Iraq \\ ${ }^{2}$ Physics Department, College of Education, Al-Mustansiriyah University, Baghdad, Iraq \\ *,**E-mail address: * saadoboudi@scbaghdad.edu.iq , ** nadirfadhil@yahoo.com
}

\begin{abstract}
Thin films of $\mathrm{ZnO}_{0.7} \mathrm{NiO}_{0.3}$ have deposited on glass substrates at room temperature by using thermal evaporation technique under vacuum $10^{-5}$ mbar. The optical properties and dispersion parameters of the films have been studied. Changes in direct optical energy band gap of films were confirmed before and after annealing. The optical energy gap $\mathrm{E}_{\mathrm{g}}$ decreased from 3.11 to $2.86 \mathrm{eV}$ with increasing of annealing temperature to $200{ }^{\circ} \mathrm{C}$. Some of the optical absorption parameters, such as optical dispersion energies $\mathrm{E}_{\mathrm{o}}$ and $\mathrm{E}_{\mathrm{d}}$, Urbach tails $\mathrm{E}_{\mathrm{U}}$, dielectric constant $\varepsilon$, the average values of oscillator strength $S_{0}$, and wavelength of single oscillator $\lambda_{o}$ have been reported. An increase in the annealing temperature causes an increase in the average oscillator strength from 62.02 to $87.71 \mathrm{eV}$.
\end{abstract}

Keywords: TCOs; Dispersion parameters; Thermal evaporation; Zinc Oxide; Nickel Oxide

\section{INTRODUCTION}

As a II-VI compound semiconductor, zinc oxide $(\mathrm{ZnO})$ is a wide-gap semiconductor with a direct band gap $\approx 3.37 \mathrm{eV}$ [1]. It has a large exciton binding energy (60 meV), which makes it promising for highly efficient optoelectronic devices even at room temperature, such as antireflection coatings, laser mirrors and monochromatic filters, as well as optoelectronics, integrated optics, solar power engineering, microelectronics and optical sensor technology depending on the reflectance and transmittance properties of the films during their preparation $[2,35]$.

To obtain high quality $\mathrm{ZnO}$ thin film, a variety of techniques have been used to prepare $\mathrm{ZnO}$ thin films including pulsed laser deposition [3, 4], molecular-beam epitaxy [5], DC magnetron sputtering [6, 7], vacuum evaporation [8], chemical-vapor deposition [9], successive ionic layer adsorption and reaction SILAR [10], chemical spray pyrolysis techniques $[11,12]$ and sol-gel techniques [13].

Snow is one of the versatile and technologically important semiconductor materials because of its typical properties such as transparency in the visible range, high electrochemical stability, absence of toxicity, abundance in nature etc. [14]. NiO on the other hand is a transition metal oxide that has several potential applications, such as solar thermal absorber, electrodes for battery and photoelectron-catalysts [15]. NiO thin films are promising 
materials with excellent electrochromic properties. Another important application of Nickel oxide films includes preparation of alkaline batteries (as cathode material), antiferomagnetic layers and P-type transparent conducting films [16]. The appealing electronic properties of $\mathrm{NiO}$ such as large band-gap energy of $(\approx 4.00) \mathrm{EV}$, and high thermal stability, make it a favorable material for electronic device applications [17].

For instance, work has been done on the composition and optical characterization of $\mathrm{ZnO}-\mathrm{NiO}$ multilayer thin films using chemical bath deposition method [18], microstructure, electrical and optical properties of $\mathrm{ZnO}-\mathrm{NiO}-\mathrm{SiO}_{2}$ nanocomposite synthesized by Sol-Gel Technique [19]. Other work carried out in this area includes synthesis and characterization of $\mathrm{ZnO}-\mathrm{NiO}$ composite nano particles by solution method [20]. While in this paper the influence of annealing temperature on the optical dispersion parameters of $\mathrm{ZnO} \mathrm{NiO}$ thin films prepared by thermal evaporation technique were characterized.

\section{EXPERIMENTAL DETAILS}

$\mathrm{ZnO}$ doped $\mathrm{NiO}$ thin films were prepared by thermal evaporation technique onto glass substrates under vacuum $10^{-5}$ mbar using (Edwared E434) coating system. The $\left(\mathrm{ZnO}_{0.7} \mathrm{NiO}_{0.3}\right)$ compound was synthesized from pure materials is not less than $(99.99 \%)$ and then weighting each element according to the density $\left(\rho \mathrm{ZnO}=6.7 \mathrm{~g} / \mathrm{cm}^{3}\right)$ and $\left(\rho \mathrm{NiO}=3.24 \mathrm{~g} / \mathrm{cm}^{3}\right)$ by using sensitive electrical balance type (Mettler H35AR), then mixing these two elements. The required weight of $\mathrm{ZnO}_{0.7} \mathrm{NiO}_{0.3}$ powder was put in a boat mounted under the funnel between two electrodes in the vacuum chamber. The substrates were fixed in a spherical holder and placed in position at a height of about $16 \mathrm{~cm}$ above the boat. When the system is pumped down to a vacuum of $10^{-5} \mathrm{mbar}$, an electric current was passed through the boat gradually to prevent breaking the boat, when the boat temperature reached the required temperature the deposition process starts with a constant deposition rate. After these steps the current supply was switched off and the samples were left in the high vacuum for one day, and then the air was admitted to the chamber, and the films were taken out of the coating unit and kept in the vacuum desiccators until the measurements were made. The thickness of films was $220 \mathrm{~nm}$.

The structural properties were determined by X-ray diffraction (XRD) using CuKa radiation of wavelength $1.54 \AA$, the current was $20 \mathrm{~mA}$, the voltage was $30 \mathrm{kV}$, and the scanning angle $2 \theta$ was varied in the range of (20-50) degree with the speed of $2 \mathrm{~cm} \cdot \mathrm{min}^{-1}$. Optical transmittance was recorded with a double beam Shimadzu UV-visible spectrophotometer in the wavelength range 300-1100 $\mathrm{nm}$. In this work the main parameter that controls the properties of the films are the annealing temperatures $(100,150 \text {, and } 200)^{\circ} \mathrm{C}$. The effect of annealing temperatures on the optical dispersion characterization of nanoparticles $\mathrm{ZnO}-\mathrm{Ni}$ thin films were examined.

\section{RESULTS AND DISCUSSION}

The optical properties of $\mathrm{ZnO}_{0.7} \mathrm{NiO}_{0.3}$ thin films by means of optical absorption in the UV to Vis region of (300-1100) nm have been investigated. The absorption coefficient $(\alpha)$ could be calculated by using the following relation [21]: 


$$
\alpha=\frac{2.303 A}{t}
$$

Where (A) is the absorption and ( $\mathrm{t}$ ) is the film thickness.

Fig. 1. Shows the dependence of the absorption coefficient $(\alpha)$ on the wavelength. The effect of annealing temperature on the absorption coefficient of the films has been investigated. It can be seen from the figure that the absorption coefficient $(\alpha)$ decreases with the increasing of wavelength. This behavior suggests decreasing in the energy gap with the increasing of annealing temperature. From this figure, the region of higher values of $\alpha$, that is $\alpha>10^{4} \mathrm{~cm}^{-1}$ correspond to transition between extended state in both valence and conduction bands, while the lower values, that is $\alpha \leq 10^{4} \mathrm{~cm}^{-1}$ is the region where absorption present a rough exponential behavior, which could be attributed to the lattice absorption bands correspond to the electronic transitions between the highest filled energy band to the lowest empty band. Similar types of results was reported by Ajuba et al. [22].

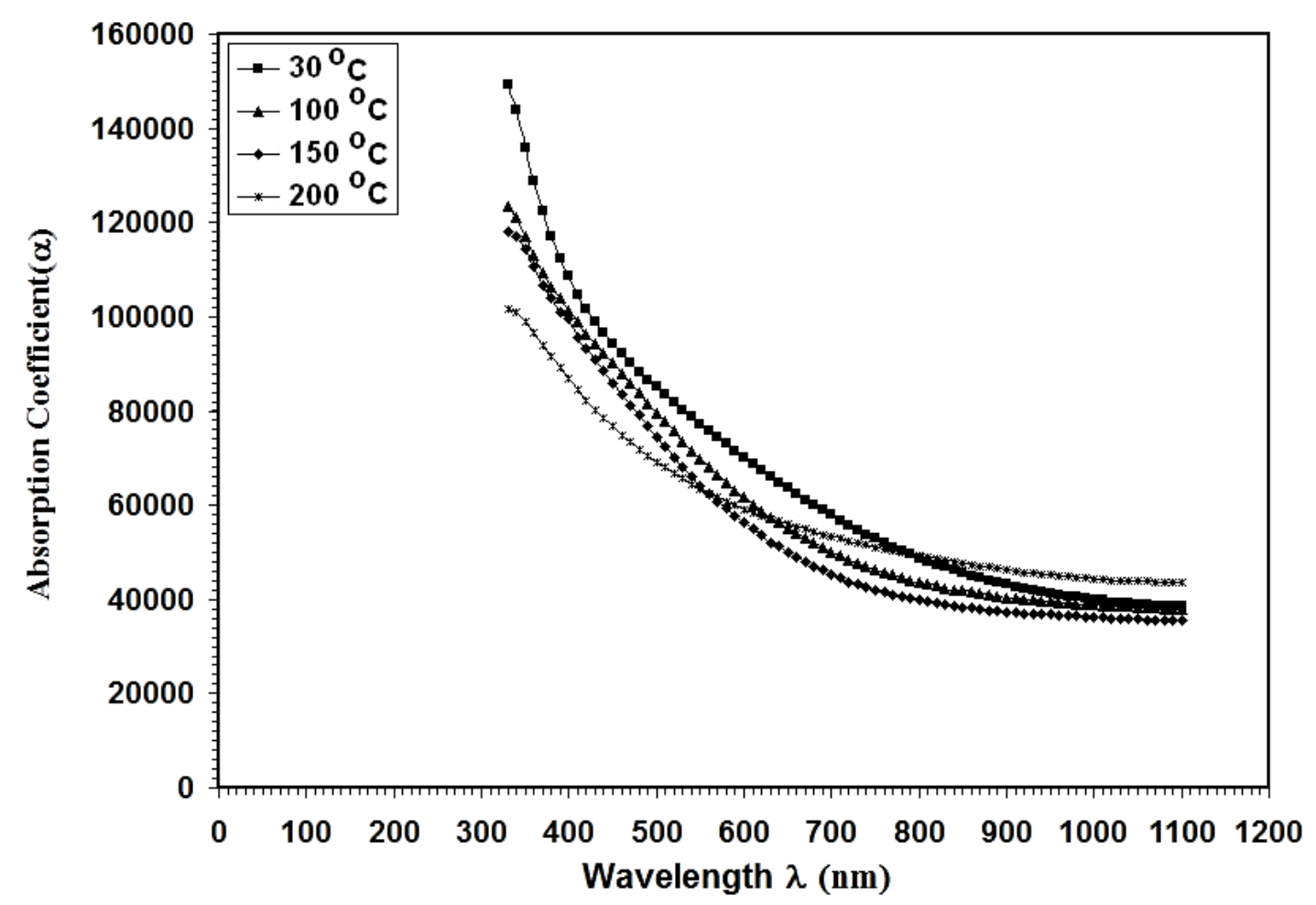

Fig. 1. Absorption coefficient as a function of wavelength for $\mathrm{ZnO}_{0.7} \mathrm{NiO}_{0.3}$ thin films at different annealing temperatures.

From the transmittance data and according to Tauc [23] relation, $(\alpha h v)^{2}$ versus incident photon energy (hv), plots were obtained. The graphs are represented in Figure 2, which shows the direct optical energy gap of $\mathrm{ZnO}_{0.7} \mathrm{NiO}_{0.3}$ thin films at room temperature and after annealed to different annealing temperature $(100,150,200)^{\circ} \mathrm{C}$. From this figure, we can see that the value of energy gap $\mathrm{E}_{\mathrm{g}}$ decreases with increasing of annealing temperature. This is possibly due to the crystal growth and reorganization of the films. Such result was obtained by Lokhande et al., they showed that the energy gap was affected by the thickness of the film and its crystallite size [24]. 

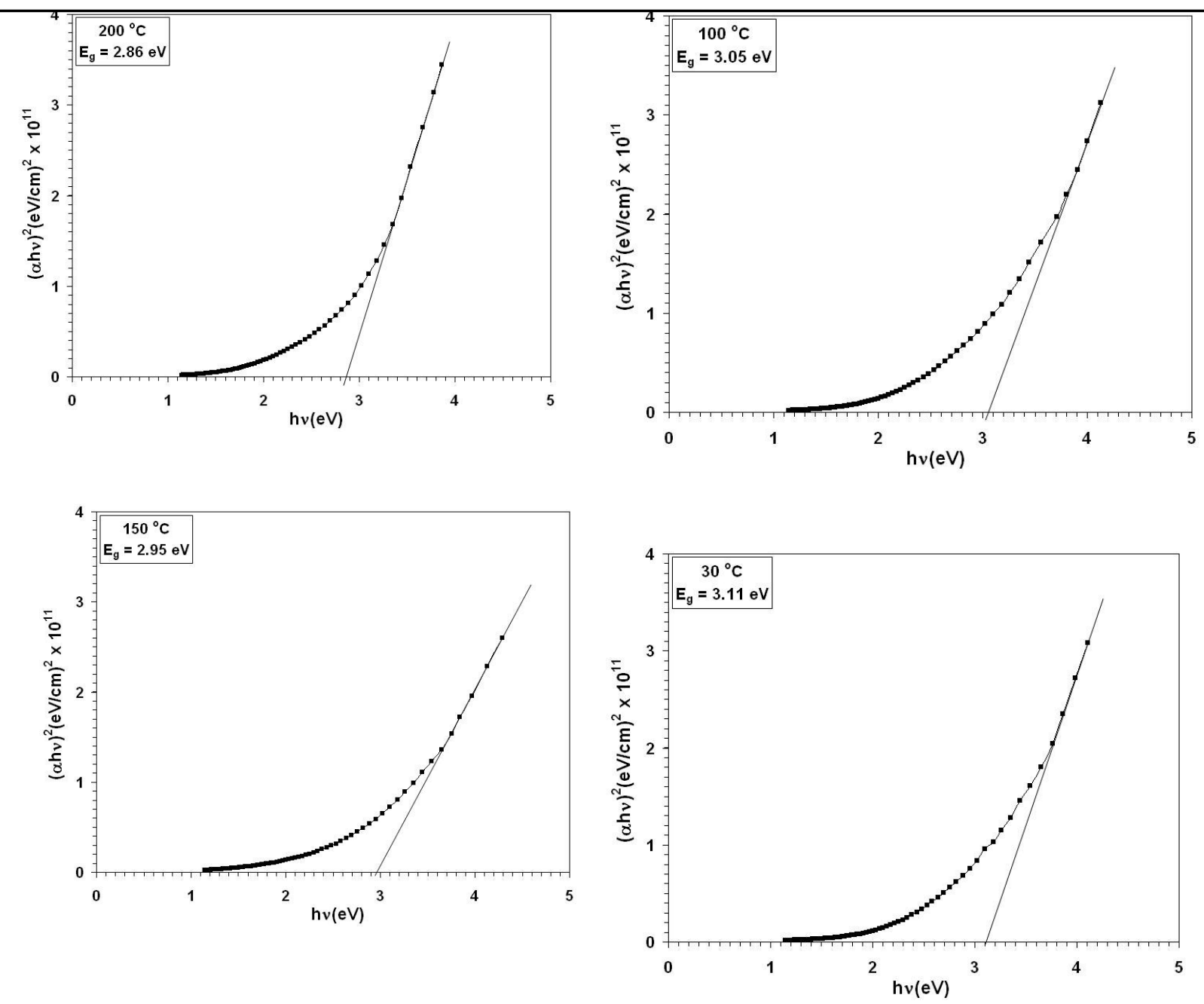

Fig. 2. Variation of $(\alpha h v)^{2}$ with photon energy for $\mathrm{ZnO}_{0.7} \mathrm{NiO}_{0.3}$ thin films.

The incorporation of impurity into the semiconductor often reveals the formation of band tailing in the band gap. The tail of the absorption edge is exponential, indicating the presence of localized states in the energy band gap. The amount of tailing can be predicted to a first approximation by plotting the absorption edge data in terms of an equation originally given by Urbach [25], which is related directly to a similar exponential tail for the density of states [26].

The absorption edge gives a measure of the energy band gap and the exponential dependence of the absorption coefficient, in the exponential edge region Urbach rule is expressed as [27, 28]:

$$
\alpha=\alpha_{\mathrm{o}} \exp \left(\mathrm{hv} / \mathrm{E}_{\mathrm{U}}\right)
$$

Where $\alpha_{0}$ is a constant, $E_{U}$ is the Urbach energy, which characterizes the slope of the exponential edge. Figure 3, shows Urbach plots of the films. The value of $\mathrm{E}_{\mathrm{U}}$ was obtained from the inverse of the slope of ln $\alpha$ vs. hv and is given in Table 1. The dopants change the width of the localized states in the optical band. 
$E_{U}$ values change inversely with the optical band gap. The Urbach energy values of the films were calculated to be increased from 641 to 775 me as increasing annealing temperature to $200^{\circ} \mathrm{C}$.

The increase in $\mathrm{E}_{\mathrm{U}}$ is attributed to the increase of disorder of the material occurred by doping. This increase leads to a redistribution of the states, from band to tail, thus allows for a greater number of possible bands to tail and tail to tail transitions [29]. As a result, both a decrease in the optical gap and a broadening of the Urbach tail have taken place.

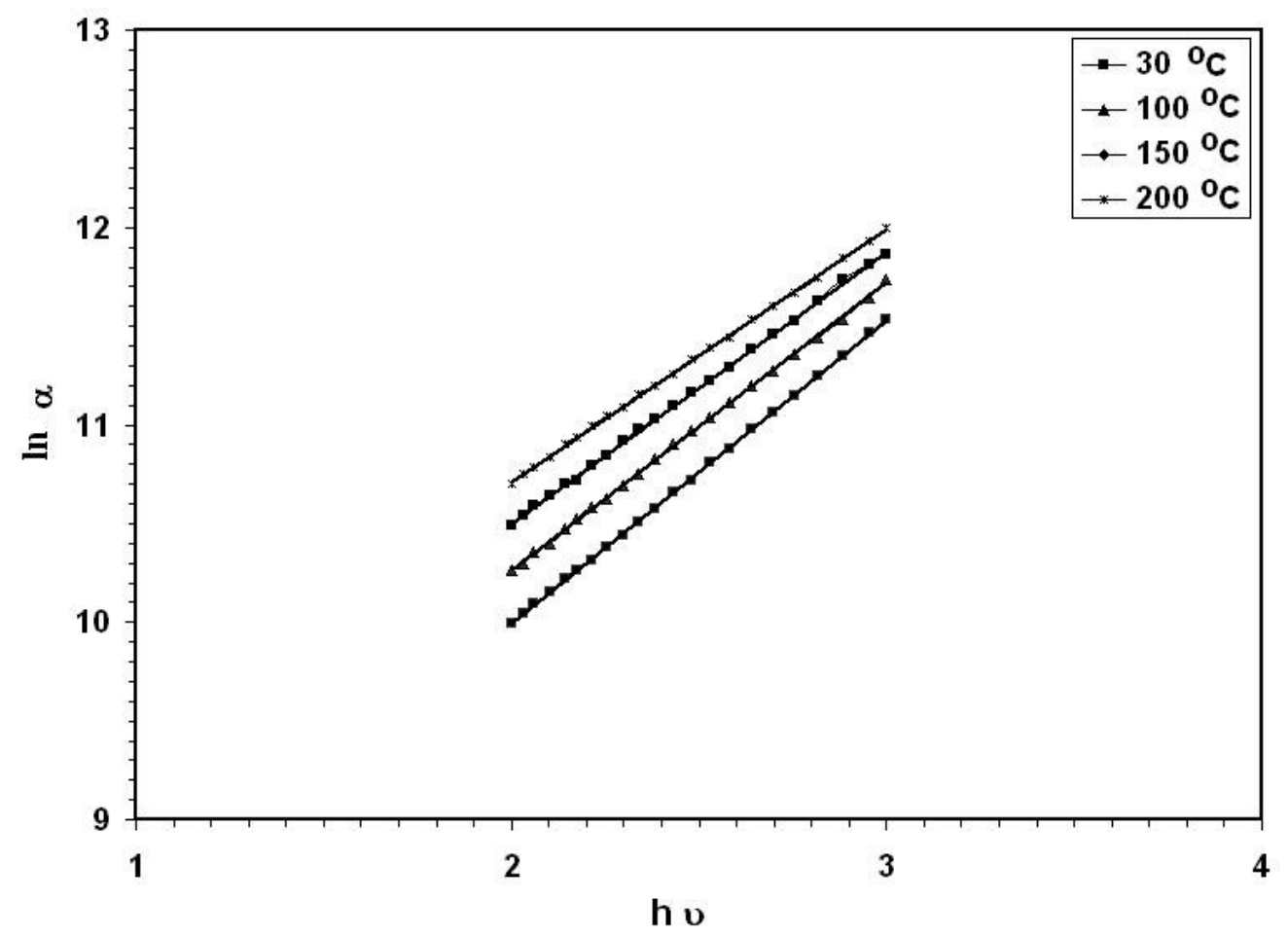

Fig. 3. $\ln \alpha$ versus photon energy for $\mathrm{ZnO}_{0.7} \mathrm{NiO}_{0.3}$ thin films.

The dispersion energy plays an important role in the research for optical materials because it is a significant factor in optical communication and in designing devices for spectral dispersion. The dispersion of refractive index in $\mathrm{ZnO}_{0.7} \mathrm{NiO}_{0.3}$ films was analyzed using the concept of the single oscillator and can be expressed by Wemple and Di-Domenico relationship [30]:

$$
n^{2}-1=\left[E_{d} E_{o} / E_{o}^{2}-E^{2}\right]
$$

The physical meaning of the single-oscillator energy $E_{o}$ is that it simulates all the electronic excitation involved and $E_{d}$ is the dispersion energy related to the average strength of the optical transitions [31]. The parameter $E_{d}$, which is the measure of the intensity of the inter band optical transition, does not depend significantly on the band gap. A plot of $\left(\mathrm{n}^{2}-1\right)^{-1}$ versus (hv) ${ }^{2}$ of $\mathrm{ZnO}_{0.7} \mathrm{NiO}_{0.3}$ deposited films for different annealing temperatures as shown in Figure 4.

It is clear that, the effect of annealing temperature on the refractive index and semiconductor dispersion profiles were exhibited a linear displacement in the shape of the 
dispersion profile with a decreasing refractive index. The refractive index declines towards long wavelengths. This is due to the influence of lattice absorption.

The values of $E_{d}$ and $E_{o}$ were obtained from the slope, $\left(E_{0} E_{d}\right)^{-1}$ and intercept $\left(E_{0} / E_{d}\right)$, on the vertical axis and are given in Table 1 . The values of $E_{o}$ was found to be decreased with increasing of annealing temperature, while the values of $E_{d}$ increased. This could be attributed to the increase in the number of scattering center due to the dissolving of iridium atoms in the film matrix.

According to the single-oscillator model, the single oscillator parameters $E_{o}$ and $E_{d}$ are related to the imaginary part of the complex dielectric constant $\varepsilon_{2}$, the moments of the imaginary part of the optical spectrum $\mathrm{M}_{-1}$ and $\mathrm{M}_{-3}$ moments can be derived from the following relations $[32,33]$ :

$$
\begin{aligned}
& \mathrm{E}_{\mathrm{o}}{ }^{2}=\mathrm{M}_{-1} / \mathrm{M}_{-3} \\
& \mathrm{E}_{\mathrm{d}}{ }^{2}=\mathrm{M}_{-1}^{3} / \mathrm{M}_{-3}
\end{aligned}
$$

The oscillator energy $E_{0}$, which was independent of the scale of $\varepsilon_{2}$ is consequently an average energy gap, whereas $\mathrm{E}_{\mathrm{d}}$ depends on the scale of $\varepsilon_{2}$ and thus serves as an interband strength parameter.

The obtained $\mathrm{M}_{-1}$ and $\mathrm{M}_{-3}$ moments changes with dopants. The values obtained for the dispersion parameters $\mathrm{E}_{\mathrm{o}}, \mathrm{E}_{\mathrm{d}}, \mathrm{M}_{-1}$ and $\mathrm{M}_{-3}$ are listed in Table 1.

For the definition of the dependence of the refractive index $\mathrm{n}$ on the light wavelength $(\lambda)$, the single-term Sellmeier relation can be used [34]:

$$
\mathrm{n}^{2}(\lambda)-1=\mathrm{S}_{\mathrm{o}} \cdot \lambda_{\mathrm{o}}^{2} / 1-\left(\lambda_{\mathrm{o}} / \lambda\right)^{2}
$$

Where $\lambda_{\mathrm{o}}$ is the average oscillator position and $\mathrm{S}_{\mathrm{o}}$ is the average oscillator strength. The parameters $S_{o}$ and $\lambda_{0}$ in Eq. (6) can be obtained experimentally by plotting $\left(n^{2}-1\right)^{-1}$ against $\lambda^{-2}$ as shown in Fig. 5, the slope of the resulting straight line gives $1 / \mathrm{S}_{0}$, and the infinitewavelength intercept gives $1 / \mathrm{S}_{\mathrm{o}} \lambda_{\mathrm{o}}^{2}$.

The results show a decrease in the band gap which may be attributed to the presence of crystal defects, that increase the density of localized states and cause a widening in the Urbach tail and consequently decrease the energy gap.

Table 1. The optical parameters.

\begin{tabular}{|c|c|c|c|c|c|c|c|c|c|c|}
\hline $\begin{array}{c}\mathrm{Ta} \\
{ }^{\circ} \mathrm{C}\end{array}$ & $\begin{array}{c}\mathrm{E}_{\mathrm{o}} \\
(\mathrm{eV})\end{array}$ & $\begin{array}{c}\mathrm{E}_{\mathrm{d}} \\
(\mathrm{eV})\end{array}$ & $\begin{array}{c}\mathrm{E}_{\mathrm{g}} \\
(\mathrm{eV})\end{array}$ & $\begin{array}{c}\mathrm{E}_{\mathrm{u}} \\
\mathrm{meV}\end{array}$ & $\varepsilon_{\infty}$ & $\mathrm{n}(\mathrm{o})$ & $\mathrm{M}_{-1}$ & $\begin{array}{c}\mathrm{M}_{-3} \\
\mathrm{eV}^{-2}\end{array}$ & $\begin{array}{c}\mathrm{S}_{\mathrm{o}} \times 10^{13} \\
\mathrm{~m}^{-2}\end{array}$ & $\lambda_{\mathrm{o}} \mathrm{nm}$ \\
\hline 30 & 6.20 & 62.02 & 3.10 & 641 & 11.00 & 3.32 & 10.00 & 0.26 & 9.32 & 391 \\
\hline 100 & 6.03 & 75.38 & 3.02 & 680 & 13.50 & 3.67 & 12.50 & 0.34 & 9.29 & 423 \\
\hline 150 & 5.98 & 79.68 & 2.99 & 724 & 14.30 & 3.79 & 13.30 & 0.37 & 8.57 & 452 \\
\hline 200 & 5.70 & 87.71 & 2.85 & 775 & 16.00 & 4.05 & 15.38 & 0.47 & 6.94 & 526 \\
\hline
\end{tabular}




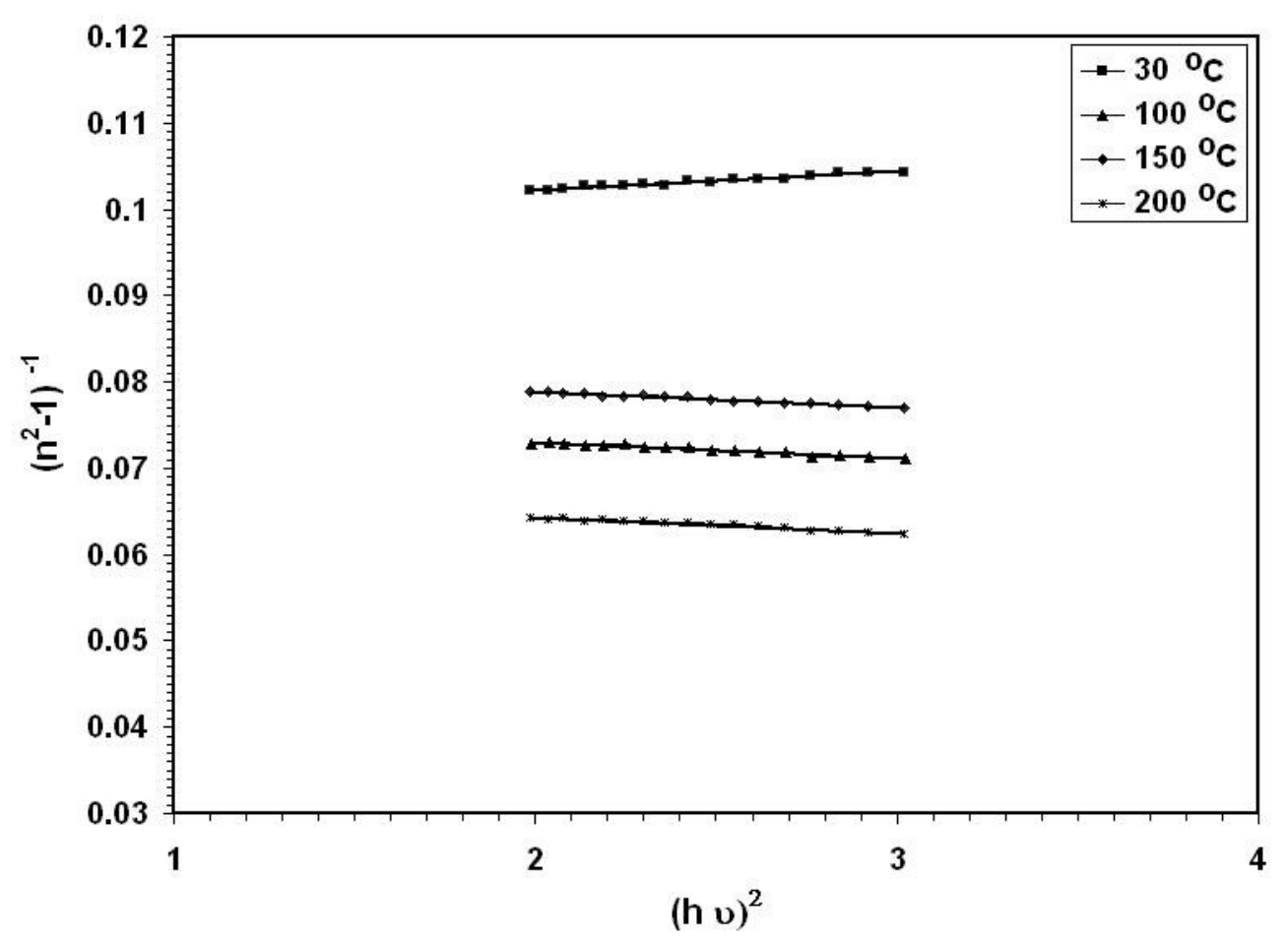

Fig. 4. Variation in $\left(\mathrm{n}^{2}-1\right)^{-1}$ as a function of $(\mathrm{hv})^{2}$ for $\mathrm{ZnO} / \mathrm{NiO}$ thin films.

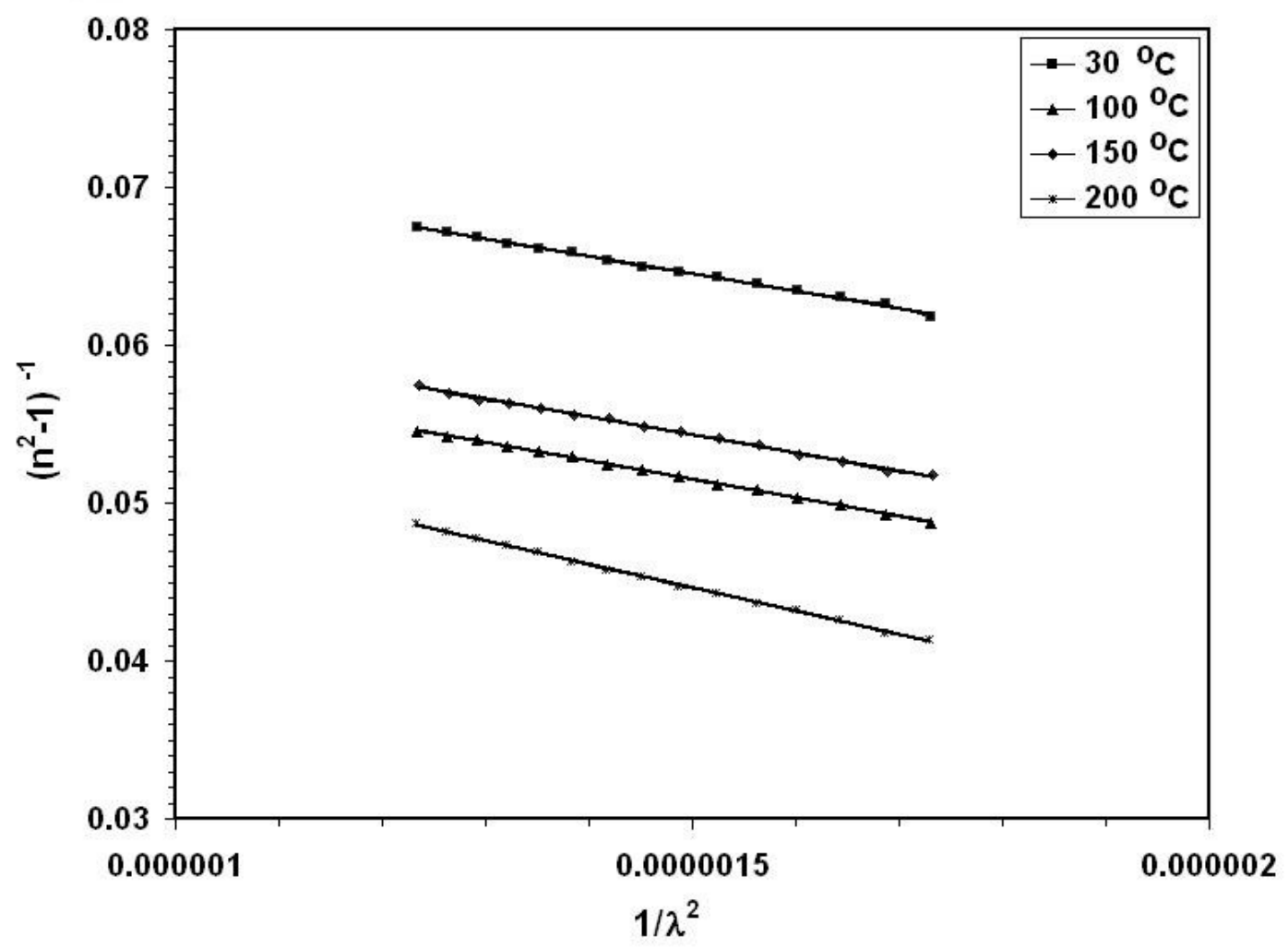

Fig. 5. Variation in $\left(n^{2}-1\right)^{-1}$ as a function of $(\lambda)^{-2}$ for $\mathrm{ZnO} / \mathrm{NiO}$ thin films. 


\section{CONCLUSION}

$\mathrm{ZnO}_{0.7} \mathrm{NiO}_{0.3}$ thin films were prepared by using thermal evaporation technique. The refractive index of the prepared films depends on the annealing temperature. The optical band gap decreased due to increasing annealing temperature. The single-oscillator parameters were determined. It was shown that the dispersion parameters of the films obeyed the single oscillator model, the change in dispersion was investigated and its value decreased from 6.20 to $5.70 \mathrm{eV}$ for films with increasing annealing temperature to $200{ }^{\circ} \mathrm{C}$.

\section{References}

[1] C. Klinshirn, Physica Status Solidi (b) 244 (2007) 3027-3073, DOI: $10.1002 / \mathrm{pssb} .200743072$.

[2] C. F. Windisch Jr., K. F. Ferris, G. J. Exarhos, J. Vac. Sci. Technol. A 19(4) (2001) 1647-1651.

[3] Akio Suzuki, Tatsuhiko Matsushita, Yoshiaki Sakamoto, Naoki Wada, Tomoya Fukuda, Hideki Fujiwara, Masahiro Okuda, Jpn. J. Appl. Phys. 35 (1996) $5457-5461$.

[4] S. Hayamizu, H. Tabata, H. Tanaka, T. Kawai, J. Appl.Phys. 80 (1996) 787, http://dx.doi.org/10.1063/1.362887.

[5] H.-J. Ko, T. Yao, Y. Chen, S.-K. Hong, J. Appl. Phys. 92, 4354 (2002) 61-68.

[6] Masato Kon, PungKeun Song, Akira Mitsui, Yuzo Shigesato, Jpn. J. Appl. Phys. 41 (2002) 6174-6179.

[7] Quan-Bao Ma, Zhi-Zhen Ye, Hai-Ping He, Shao-Hua Hu, Jing-Rui Wang, Li-Ping Zhu, Yen-Zhu Zhang, Bing-Hui Zhao, J. of Crystal Growth 304 (2007) 64-68.

[8] Tadatsugu Minami, Satoshi Ida, Toshihiro Miyata, Youhei Minamino, Thin Solid Films 445 (2003) 268-273.

[9] Li, Y., Tompa, G. S., Liang, S., Gorla, C., Lu, Y., Journal of Vacuum Science \& Technology A 15 (1997) 1063-1068.

[10] SeppoLindroos, MarkkuLeskela, International Journal of Inorganic Materials 2 (2000) 197-201.

[11] K. T. Ramakrishna Reddy, H. Gopalaswamy, P. J. Reddy, R. W. Miles, J. of Crystal Growth 210 (2000) 516-520.

[12] K. T. Ramakrishna Reddy, T. B. S. Reddy, I. Forbes, R. W. Miles, Surface and Coatings Technology 151-152 (2002) 110-113.

[13] Jin-Hong Lee, Byung-Ok Park, Thin Solid Films Vol. 426 (1-2) (2003) 94-99.

[14] V. R. Shinde, C. D. Lokhande, R. S. Mane, H. Sung-Hwan, Applied Surface Science 245 (2005) 407-413.

[15] S. V. Han, D. H. Lee, V. J. Chang, S. O. Ryu, T. J. Lee, C. H. Chang., Journal of the Electrochemical Society 153(6), (2006) 382. 
[16] Q. Y. Li, R. N. Wang, Z. R. Nie, Z. H. Wang, Q. Wei, Journal of Colloid and Interface Science 320 (2008) 254-258.

[17] S. R. Krishnakumar, M Liberati, C. Grazioli. M. Veronese, S. Turchini, P. Luches, S. Valeri, C. Carbone, J. of Magnetism and Magnetic Materials 310 (2007) 8-12.

[18] Ajuba A. E., Ezugwu S. C., Asogwa P. U., Ezema F. I., Chalcogenide Letters 7(10) (2010) 573-579.

[19] A. C. Canan, A. Ayse, Turkish Journal of Science and Technology 4(2), (2009) 121.

[20] Ashwani Sharma, Pallavi, Sanjay Kumar, Nano Vision 1(3) (2011) 115-122.

[21] Han X., Liu R., Chen W., Xu Z., Thin Solid Films 516 (2008) 4025- 4029.

[22] A. E. Ajuba, S. C. Ezugwu, P. U. Asogwa, F. I. Ezema, Chalcogenide Letters 7(10) (2010) 573-579.

[23] J. Tauc, Amorphous and Liquid Semiconductors, Plenum Press, New York, 1974.

[24] Lokhande C. D., Lee E. H., Jung K. D., Joor O. S., Material Chemical and Physics $91(2005) 200$.

[25] Urbach F., Phys. Rev. 92(5) (1953) 1324.

[26] Cody G. D., J. Non-Cryst. Solids 141 (1992) 3-15.

[27] J. Tauc, “Amorphous and Liquid Semiconductors," Plenum Press, New York, 1974.

[28] J. Tauc, R. Grigorovici, A. Vancu, Phys. Status Solidi 15 (1966) 627-637.

[29] S. K. O’Leary, S. Zukotynski, J. M. Perz, J. Non-Cryst. Solids 210 (1997) 249.

[30] S. H. Wemple, M. DiDomenco, Physical Review B 3 (1971) 1338-1342. doi:10.1103/PhysRevB.3.1338.

[31] Wemple S. H., Phys. Rev. B 7 (1973) 3767-3777.

[32] Atyia H. E., Optoelectron. Adv. M. 8 (2006) 1359-1366.

[33] M. Caglar, S. Ilican, Y. Calgan, Y. Sahin, F. Yakuphanoglu, D. Hur, Spectrochimica Acta A 71(2) (2008) 621-627, doi:10.1016/j.saa.2008.01.022.

[34] Wemple S. H., Di Domenico J. Appl. Phys. 40 (2) (1969) 720-734.

[35] Nadir Fadhil Habubi, Sami Salmann Chiad, Saad Farhan Oboudi, Ziad Abdulahad Toma, International Letters of Chemistry, Physics and Astronomy 4 (2013) 1-8. 